\title{
PEMETAAN DAERAH RAWAN LONGSOR DENGAN MENGGUNAKAN SISTEM INFORMASI GEOGRAFIS STUDI KASUS KABUPATEN BONDOWOSO
}

\author{
Moch. Fauzan Dwi Harto, Adhitama Rachman, Putri Rida L, Maulidah Aisyah, Haris Purna W, \\ Nathasya Abigail dan Fadlillah Nur R, Widya Utama \\ Teknik Geofisika, Fakultas Teknik Sipil, Lingkungan dan Kebumian, Institut Teknologi Sepuluh Nopember Surabaya \\ e-mail : fauzandwiharto@gmail.com
}

\begin{abstract}
Abstrak. Kabupaten Bondowoso merupakan daerah yang berpotensi terjadi bencana tanah longsor. karena memiliki kemiringan lereng curam (> 25\%) dengan jenis tanah dominan adalah andosol yang memiliki sifat peka erosi dan curah hujan tahun 2013 lebih dari 1500 mm. Pemetaan menggunakan tujuh parameter yaitu kemiringan lereng, curah hujan, tata guna lahan, geologi, kedalaman solum, tekstur tanah, permeabilitas tanah.dan masing-masing memiliki skor dan bobot kemudian dilakukan overlay sehingga menghasilkan peta sebaran daerah rawan longsor. Pengerjaan analisis dengan SIG dalam pemetaan zona kerentanan gerakan tanah secara tidak langsung, dilakukan dengan menggunakan software Arcview. Software ini digunakan untuk menghitung persentase kemiringan lereng, dan menghitung dan mengevaluasi unit, klas atau tipe mana dari setiap individu peta yang penting (berpengaruh) terhadap kejadian gerakan tanah. Hasil Penelitian didapatkan daerah yang sangat rawan terkena longsor yaitu telogosari, wringin, tegalampel, pakem, dan maesan.
\end{abstract}

Kata Kunci : Pemetaan, Rawan Longsor, Sistem Informasi Geografi

\begin{abstract}
Bondowoso regency is a potential area of landslide disaster. Because it has a steep slope (> 25\%) with the dominant soil type is andosol that has erosion sensitive nature and rainfall in 2013 more than $1500 \mathrm{~mm}$. Mapping using seven parameters ie slope, rainfall, land use, geology, solum depth, soil texture, soil permeability.and each has a score and weight then overlayed to produce a map of the spread of landslide prone areas. The analysis work with GIS in mapping of land susceptibility zones indirectly, is done using Arcview software. This software is used to calculate the slope percentage, and calculate and evaluate which units, classes or types of individual maps are important (influential) to the occurrence of ground motion. The result of this research is got area which is very vulnerable to landslide that is telogosari, wringin, tegalampel, pakem, and maesan.
\end{abstract}

Keywords : Mapping, Potential Area Landslide Disaster, Geographic Information System

\section{PENDAHULUAN}

Wilayah Indonesia terletak di garis khatulistiwa sehingga banyak menerima panas matahari dan curah hujan yang tinggi, oleh karena itu Indonesia menjadi rawan terhadap bencana alam hidro-meteorologi seperti banjir, kekeringan, gelombang laut besar, dan sebagainya. Badan Nasional Penanggulangan Bencana (BNPB) mencatat dari total bencana hidrometeorologi yang paling sering terjadi di Indonesia adalah bencana banjir diikuti oleh longsor.

Tanah longsor adalah suatu gerakan menuruni lereng oleh massa tanah dan atau batuan penyusun lereng. Gerakan tanah merupakan salah satu proses geologi yang terjadi akibat interkasi beberapa kondisi antara lain geomorfologi, struktur geologi, hidrogeologi dan tata guna lahan. Kondisi yang saling berpengaruh tersebut dapat mewujudkan kondisi lereng yang cenderung bergerak (Karnawati, 2005). Pergerakan tanah dapat diketahui dengan tanda-tanda seperti munculnya retak tarik dan kerutan di permukaan lereng, miringnya pepohonan, hilangnya kelurusan fondasi bangunan dan lainnya (Hardiyatmo,2012). Pembuatan peta rawan longsor dapat menggunakan Sistem Informasi Geografis, sehingga dapat diketahui daerah yang terdampak (Firdaus dan Sukojo, 2015)

\section{METODOLOGI}

Berdasarkan Keputusan Menteri Energi dan Sumberdaya Mineral No.1452/K/10/MEM/2000 tentang Pedoman Teknis Pemetaan Zona Kerentanan Gerakan Tanah, pemetaan zona 
kerentanan tanah dapat dilakukan dengan pemetaan langsung, pemetaan tidak langsung dan metoda gabungan. Dalam penelitian ini penulis menggunakan metode pemetaan tidak langsung.

Metode tidak langsung adalah dengan prosedur analisis tumpang tindih (overlaying) untuk mencari pengaruh faktor-faktor yang terdapat pada peta-peta parameter terhadap sebaran (distribusi) gerakan tanah, kemudian dengan analisis menggunakan SIG (Sistem Informasi Geografis) dapat ditentukan zonasi kerentanan gerakan tanahnya.

Pengerjaan analisis dengan SIG dalam pemetaan zona kerentanan gerakan tanah secara tidak langsung, dilakukan dengan menggunakan software Arcview. Software ini digunakan untuk menghitung persentase kemiringan lereng, dan menghitung dan mengevaluasi unit, klas atau tipe mana dari setiap individu peta yang penting (berpengaruh) terhadap kejadian gerakan tanah.

Berikut Diagram Alir Prosedur analisa gerakan tanah dengan menggunakan GIS :

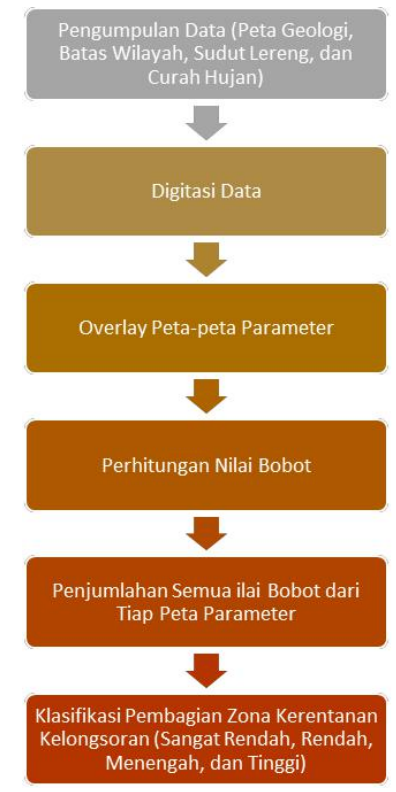

Gambar 1 Diagram Alir Prosedur analisa gerakan tanah dengan menggunakan GIS

Berikut ini akan diuraikan beberapa tahapan dalam studi khusus kerentanan gerakan tanah menggunakan SIG :

1. Tahap pengumpulan data

Dalam tahapan ini dilakukan pengumpulan data-data berupa data geologi, batas wilayah, kemiringan lereng, dan curah hujan. Data-data tersebut umumnya dalam bentuk raster.

2. Pengolahan Data

Pengolahan data meliputi konversi peta. Kegiatan konversi peta dimaksudkan agar peta analog/bentuk raster terkonversi menjadi peta digital/vektor (shp) yang lazim dinamakan digitasi. Setiap obyek dalam peta digital baik berupa titik (misalnya : titik ketinggian), unsur garis (misalnya : jalan, sungai), juga unsur poligon (misalnya : pemukiman, hutan) memuat data non-grafis (atribut) berupa informasi-informasi tekstual kedalam database.

\section{Analisa}

Kegiatan ini mencakup proses pembentukan query (perintah pengambilan dan analisis data) dengan menggunakan fasilitas fungsi yang ada pada sistem tersebut. Peta-peta tematik hasil digitasi, dianalisis dengan metode tumpang tindih (overlaying). Tumpang tindih dilakukan antara petapeta parameter (geologi, batas wilatah, sudut lereng, dan curah hujan) terhadap peta distribusi gerakan tanah. Dari hasil tumpang tindih tersebut dilakukan perhitungan nilai bobot (weight value) dengan menggunakan metode kuantitatif (metode statistik) sebagai metode pendekatan.

Dalam kegiatan ini, dilakukan analisa data berdasarkan data yang tersedia dengan memperhatikan faktor - faktor pemicu terjadinya bencana. Faktor-faktor yang diperhitungkan disini adalah :

- Faktor kelerengan

Kemiringan dan ketinggian suatu lereng, sangat mempengaruhi kemantapannya. Semakin besar kemiringan dan ketinggian suatu lereng, maka kemantapannya berkurang. 


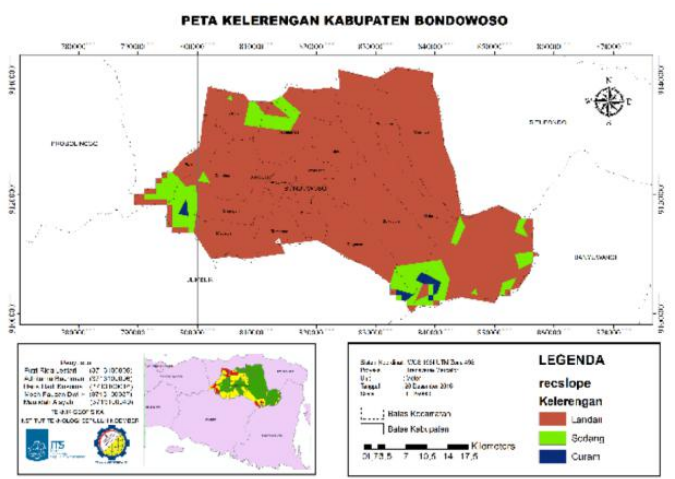

Gambar 2 Peta Kelerengan Wilayah Kabupaten Bondowoso (sumber : penulis)

Tabel 1

Luas Wilayah Kecamatan menurut Klasifikasi Lereng

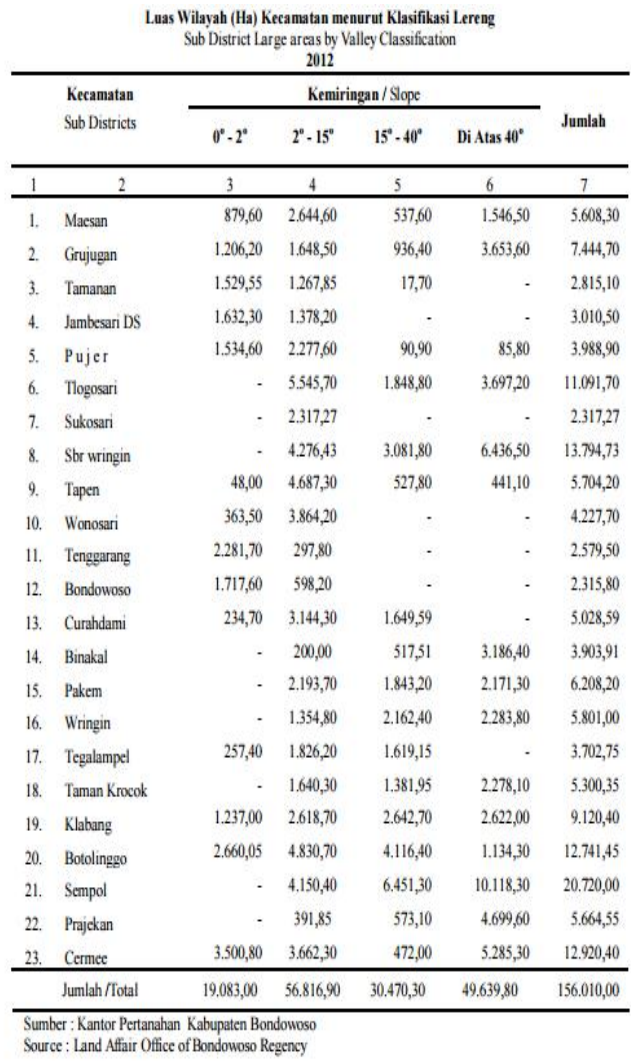

- Faktor curah hujan

Iklim juga mempengaruhi kemantapan suatu lereng. Hal ini disebabkan karena iklim mempengaruhi perubahan temperatur, jumlah hujan per tahun, dan yang terpenting, iklim juga mempengaruhi tingkat pelapukan, maka kekuatan batuan atau tanah menjadi semakin kecil.

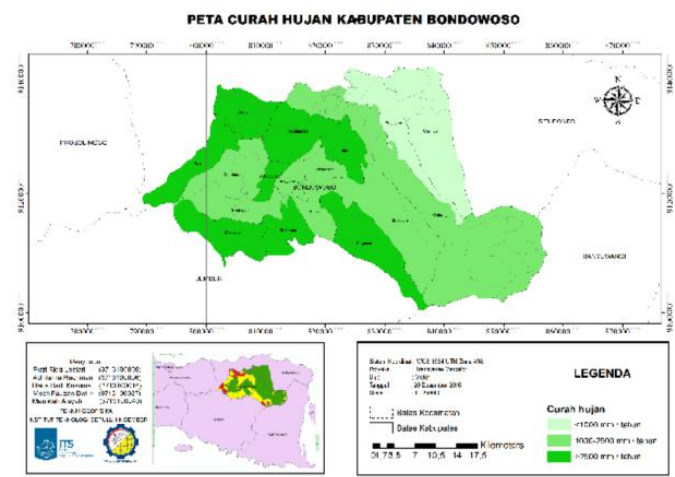

Gambar 3. Peta Curag Hujan Wilayah Kabupaten Bondowoso (Sumber : penulis)

Tabel 2

Banyaknya Curah Hujan menurut Stasiun Pengukuran

\begin{tabular}{|c|c|c|c|c|c|c|c|c|c|}
\hline \multicolumn{2}{|c|}{$\begin{array}{l}\text { Kecamatan } \\
\text { Sub Districts }\end{array}$} & $\begin{array}{c}\text { Stasiun } \\
\text { Pengukur } \\
\text { Measuring Tool }\end{array}$ & $\begin{array}{l}\text { Jan, } \\
\text { Jan, }\end{array}$ & $\begin{array}{l}\text { Feb, } \\
\text { Feb, }\end{array}$ & $\begin{array}{l}\text { Maret } \\
\text { March }\end{array}$ & $\begin{array}{l}\text { April } \\
\text { April }\end{array}$ & $\begin{array}{l}\text { Mei } \\
\text { May }\end{array}$ & $\begin{array}{l}\text { Juni } \\
\text { June }\end{array}$ & $\begin{array}{l}\text { Juli } \\
\text { July }\end{array}$ \\
\hline & (1) & (2) & (3) & (4) & (5) & (6) & (7) & $(8)$ & (9) \\
\hline 1. & Macsan & Maesan & 597 & 235 & 524 & 62 & 20 & 55 & 10 \\
\hline \multirow[t]{3}{*}{2,} & Grujugan & Grujugan & 303 & 173 & 173 & 91 & 57 & 30 & 20 \\
\hline & & & 38 & & & 6 & 78 & 17 & \\
\hline & & Clangk: & 72 & & 51 & 136 & 49 & 31 & 6 \\
\hline 3. & Tamanan & Tamana & 653 & 202 & 34 & 59 & 21 & 42 & 9 \\
\hline \multirow[t]{3}{*}{ 4, } & Pujer & Sukokerto & 403 & 332 & 299 & 193 & 80 & 0 & 5 \\
\hline & & Kejayan & 362 & 284 & 137 & 46 & 123 & 16 & . \\
\hline & & Maskuning Wetan & 439 & 207 & 248 & 62 & - & 4 & - \\
\hline \multirow[t]{2}{*}{5 , } & Tlogosari & Pakisan & 511 & 206 & 333 & 326 & 88 & 26 & 1 \\
\hline & & Tlogosari & 500 & 105 & 308 & 255 & 100 & 41 & . \\
\hline 6 , & Tenggarang & Kesemek & 358 & 336 & 167 & 117 & 52 & 35 & . \\
\hline \multirow{2}{*}{7} & Sukosari & Sumber Gading & 381 & 209 & 273 & 198 & 81 & 49 & 4 \\
\hline & & Pinang Pahit & 484 & 210 & 271 & 332 & 91 & 28 & : \\
\hline \multirow[t]{2}{*}{8,} & Tapen & Jeru & 339 & & 217 & 109 & 130 & 22 & \\
\hline & & $\mathrm{Ta}$ & 336 & & & 101 & 128 & 30 & \\
\hline \multirow[t]{2}{*}{ 9, } & Wonosari & $w_{s}$ & 279 & 182 & 147 & 112 & 69 & 15 & - \\
\hline & & Wonossoyo & 407 & 237 & 68 & 162 & 51 & 13 & \\
\hline 10 , & Bondowoso & $\begin{array}{l}\text { Sentral } \\
\text { (K. Pengairan) }\end{array}$ & 464 & 235 & 224 & 71 & 105 & 15 & \\
\hline \multirow{2}{*}{11 , } & Curahdami & Silolembu & 387 & & & & 109 & 28 & - \\
\hline & & An & 31 & & & & 65 & & 4 \\
\hline \multirow[t]{2}{*}{ 12, } & Wringin & Wrin & 74 & 3 & & & 10 & & \\
\hline & & Blimbing & 565 & 311 & 391 & 130 & 77 & 58 & - \\
\hline 13, & Pakem & Sbr Dumpyong & 546 & 393 & 331 & 248 & 82 & 99 & . \\
\hline 14, & Tegalampel & Klabang & 440 & 3 & & 52 & 57 & - & - \\
\hline \multirow[t]{3}{*}{15,} & Klabang & Glendengan & 303 & 1 & & 2 & 50 & 19 & - \\
\hline & & & 33 & 1 & & 22 & 45 & & - \\
\hline & & & 29 & 110 & & 5 & 38 & . & - \\
\hline \multirow[t]{3}{*}{16 , } & Prajekan & Prajeckan & 428 & 139 & & 38 & 47 & 21 & . \\
\hline & & & 223 & 56 & 108 & 42 & 39 & . & . \\
\hline & & Kolpoh & 355 & 45 & 341 & 29 & . & - & - \\
\hline \multirow[t]{6}{*}{17} & Cermee & Cermee & 203 & 47 & 199 & 14 & 11 & 15 & - \\
\hline & & Sulin & 268 & 44 & 221 & 22 & 15 & . & - \\
\hline & & $\mathrm{R}$ & 12 & 124 & & 22 & - & 75 & - \\
\hline & & & 15 & 30 & & 50 & - & . & - \\
\hline & & & 302 & 92 & & 55 & - & 19 & \\
\hline & & Jumlal & 3.909 & 71 & 9.234 & 611 & 1.968 & 812 & 59 \\
\hline
\end{tabular}

Hasil perhitungan nilai bobot setiap peta parameter dijumlahkan untuk mendapatkan nilai boot akhir. Nilai bobot akhir tersebut diselang untuk mendapatkan batas atas dari setiap zona kerentanan gerakan tanah. Dari batas atas nilai bobot tersebut, zona kerentanan gerakan tanah diklasifikasikan menjadi empat zona yaitu zona kerentanan gerakan tanah sangat rendah, rendah, menengah dan tinggi.

4. Tahap penyajian data

Dari hasil analisis di atas, dihasilkan peta zona kerentanan gerakan tanah dengan skala dan warna tertentu untuk memperjelas unur-unsur yang ditampilkan. 


\section{HASIL DAN PEMBAHASAN \\ Pembobotan}

Dalam pembuatan peta, setiap data yang digunakan diberi pembobotan yang berbeda-beda dikarenakan setiap data mempunyai daya pengaruh yang berbeda-beda. Data yang digunakan dalam pembuatan peta ini adalah nilai kelerengan, curah

Adapun klasifikasi di setiap data yang digunakan dalam pembuatan peta ini. Untuk curah hujan wilayah yang memiliki curah hujan dibawah $1.000 \mathrm{~mm} /$ tahun diberi skoring 1, $1.000-2.500$ $\mathrm{mm} /$ tahun diberi skoring 2, dan untuk diatas 2.500 $\mathrm{mm} /$ tahun diberi skoring 3. Untuk kelerengan wilayah yang sekiranya landai diberi skoring 1 , untuk wilyah yang cukup curam diberi skoring 2 dan untuk wilayah yang curam diberi skoring 3. Untuk berdasarkan peta geologi, skoring berdasarkan jenis tanah atau batuannya.

Setelah diberi skoring setiap parameter yang digunakan, maka akan terbuat peta masing-masing parameter sesuai skoring yang telah diberikan. Peta-peta tersebut kemudian digabung menjadi satu dan disesuaikan dengan pembobotannya maka dihasilkan peta kerawan longsor seperti pada gambar 4.1.

Dari peta kita bias mengetahui daerah mana saja yang mempunyai potensi longsor sesuai perhitungan penulis.

Saran dari penelitian ini antara lain:

- Perlu dilakukan penelitian lebih lanjut menggunakan metode geofisika seperti mikrotremor agar dapat dikorelasikan antara hasil pengolahan data mikrozonasi dengan data pengolahan scoring SIG.

\section{Daftar Pustaka}

Badan Geologi, 2006. Gerakan Tanah. Pusat Vulkanologi dan Mitigasi Bencana Geologi.

Dwikorita Karnawati. 2005. Bencana Alam Gerak Massa Tanah di Indonesia dan Upaya Penanggulangannya. Yogyakarta: Universitas Gajah Mada.

hujan, dan peta geologi. Dan untuk pembobotannya ialah untuk nlai kelerengan diberi bobot sebesar $50 \%$, curah hujan sebesar $40 \%$ dan peta geologi sebesar $10 \%$. Pemberian pembobotan berdasarkan factor paling mempengaruhi terjadinya longsor.

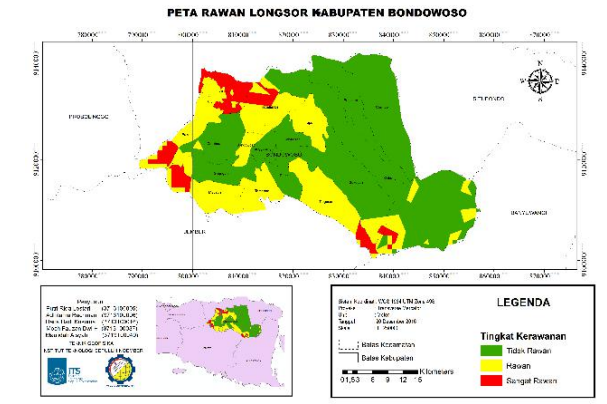

Gambar 4. Peta Kerawanan Longsor Wilayah Kabupaten Bondowoso (Sumber : penulis)

\section{PENUTUP}

\section{Kesimpulan}

Kesimpulan yang didapatkan dari penelitian ini adalah dapat diketahui daerah yang rawan terkena longsor adalah Telogosari, Wringin, Tegalampel, Pakem, dan Maesan. Tingkat kerawanan yang dibuat berdasarkan hasil skoring dibagi menjadi tiga yaitu tidak rawan yang diberi warna hijau, rawan yang diberi warna kuning dan sangat rawan yang dberi warna merah.

\section{Saran}

Firdaus, H.S., Sukojo, B.M., 2015. Pemetaan Daerah Rawan Longsor dengan Metode Penginderaan Jauh dan Operasi Berbasis Spasial, Studi Kasus Kota Batu Jawa Timur. J. Geosaintek 1, 25-34.

Hardiyatmo, H.C., 2012, Penanganan Tanah Longsor dan Erosi, Gadjah Mada University Press, Yogyakarta

www.bondowoso.go.id 

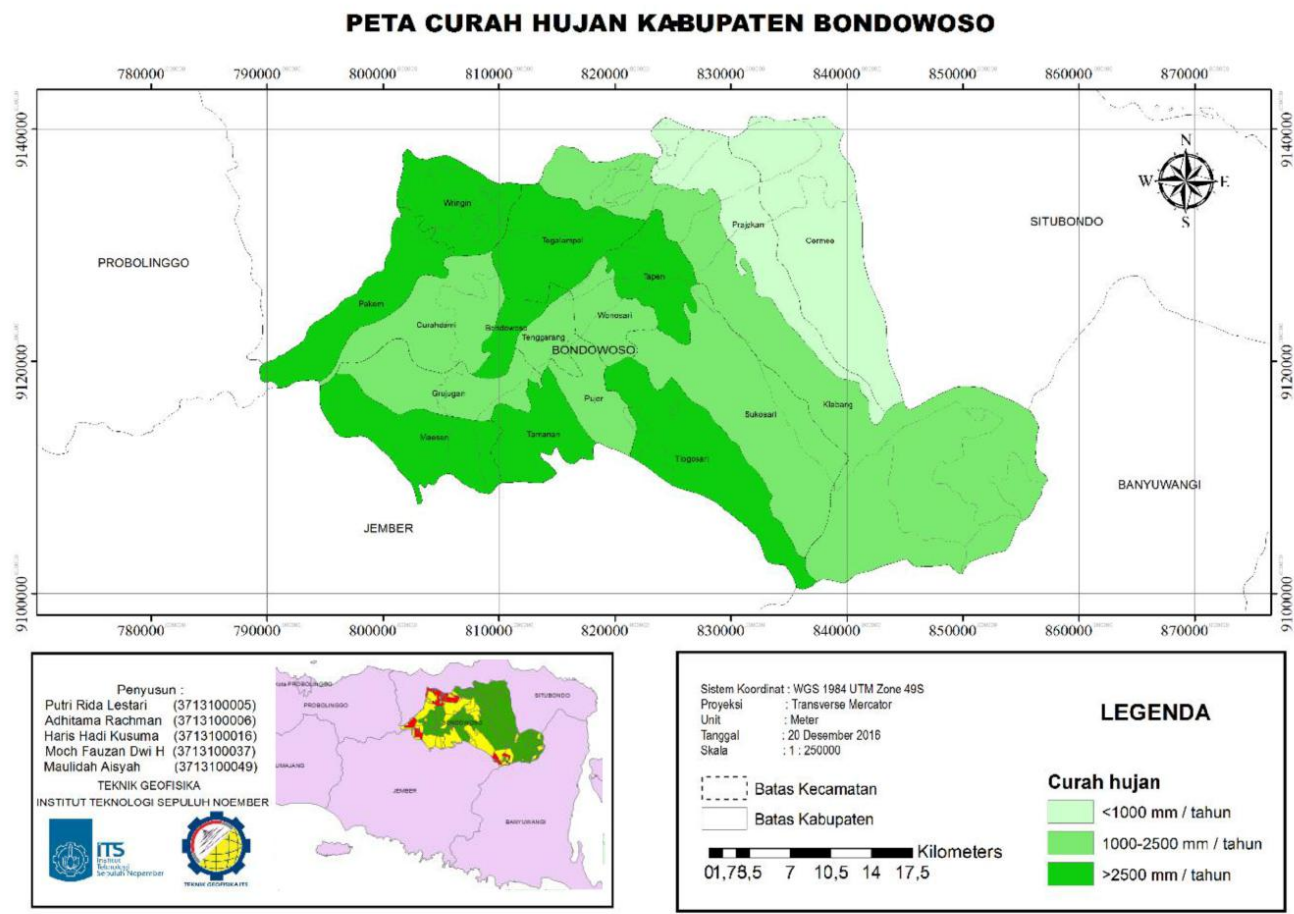

Peta Kelerengan kabupaten bondowoso

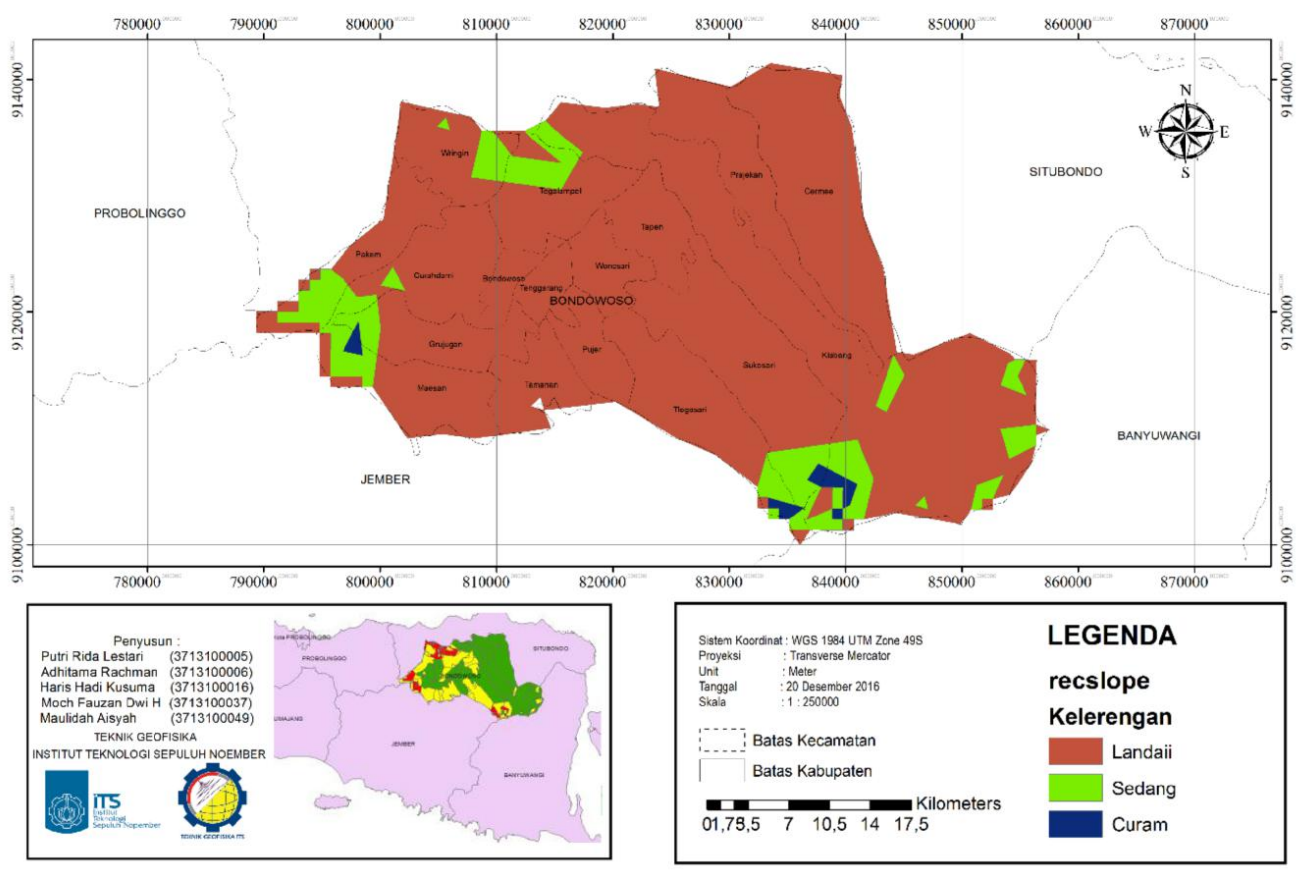


PETA RAWAN LONGSOR KABUPATEN BONDOWOSO

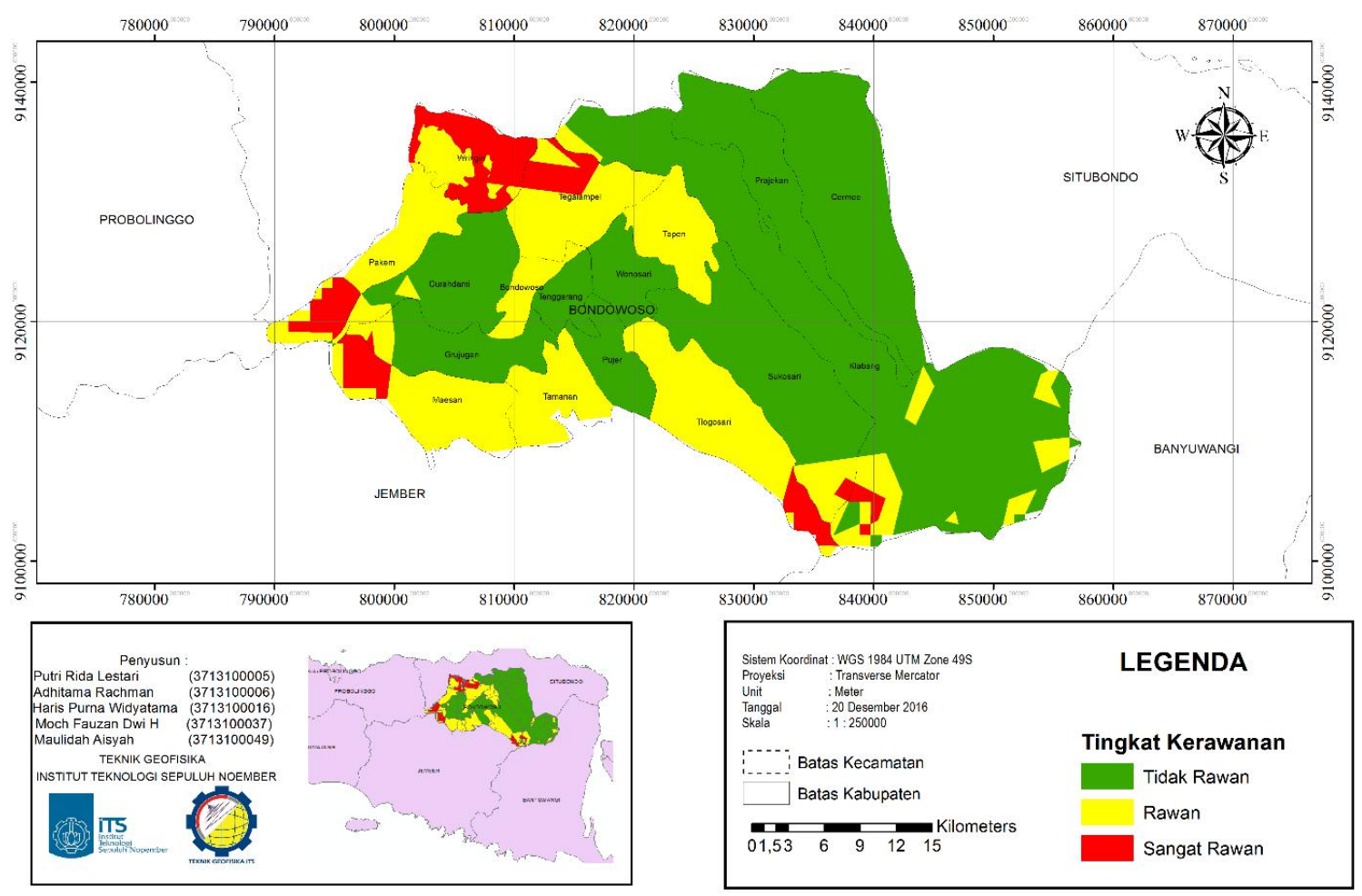

